\title{
Research on the Construction of Curriculum Resources Based on Mobile Terminal
}

\author{
Jun $\mathrm{Ma}^{1, \mathrm{a}^{*}}$ \\ School of Educational Science and Technology, Northwest University for Nationalities, Lanzhou \\ 730000, P.R. China \\ a364221500@qq.com
}

Keywords: Learner; Mobile learning; Mobile terminal; Curriculum resources; Learning pattern

\begin{abstract}
The article is the study of the construction of curriculum resources based on mobile learning platform. It put forward that curriculum resources should be rationally allocated under the pattern of mobile learning, and learning resources should be developed to appropriate mobile terminal, aiming at the problems in traditional teaching patterns of China after the analysis of experiences and learning models in some universities. Finally, it argued that curriculum resources based on mobile terminal should be constructed by the integration of mobile devices and curriculum learning resources.
\end{abstract}

\section{Introduction}

Due to the rapid update and development of mobile devices and network technology, learners have a new way of learning. At present, mobile learning has already entered our work and study, which changes the traditional learning mode and satisfies learners' desire to study at any time and everywhere [1]. Mobile learning was first proposed in the United States. Some North American and European countries study mobile learning subjects and features and develop a mobile teaching platform to realized interaction between teachers and students. How to popularize mobile learning in each college and even primary school becomes the main content of our research. First of all, technical support is needed. We need to consider whether the current technologies can help us realize this vision, and then, we need to consider how to connect our classroom learning resources with the current mobile terminal devices for interaction between teachers and students and resource sharing.

\section{Feasibility Analysis}

Popularization of Mobile Terminals at Colleges and Universities. With the constant progress of science and technology and constant expansion of the mobile device market, every student now has a mobile phone and most students have a laptop. These convenient mobile devices and resources make it possible for us to carry out mobile learning. Students' smart phones are fully utilized in learning to integrate classroom learning, digital learning and mobile learning, which is the purpose for our research into mobile learning.

Wireless Network Device in Good Conditions at Colleges and Universities. A prerequisite to realize terminal learning is network facilities. With good wireless network facilities, mobile learning can be achieved. At present, wireless network covers the entire campus at colleges and universities, which makes it possible to popularize mobile learning.

Learners Desire Mobile Learning and Teaching. Nowadays, college students are eager to have a new teaching way so that they no longer need to sit silently in the classroom listening to the teachers, but it can happen at any place. Different people have their own features, so our learning efficiency is different at different period of time. Fixed learning time and location at school restricts learners' free performance. Students expect to integrate classroom learning resources into a terminal end, so that they can learn at any time and any place. 


\section{Thought of Constructing Curriculum Learning Resources based on Mobile Terminal}

In order to construct curriculum learning resources based on mobile terminal, we should first have suitable plan, which includes research into the social environment, learners as well as mobile terminals and our courseware resources. [2] Based on research of these external factors, the next step is to study how to interconnect the courseware learning resources effectively with learners' mobile terminals.

Analysis Mobile Terminals' Features. At present, our main mobile devices are our smart phones, PC and electronic readers, etc. All these mobile devices mainly have the several following features:

Both smart phones and PDA and some other mobile devices are portable and light that learners can put them at their backpacks or handbags. Meanwhile, smart phones can usually be used for consecutive 7-10 hours and power in smart phones' battery can remain for 4-5 days with a small size, so learners can carry a battery with them.

Certain capacity of storage. PDA and smart phones not only have certain storage capacity, but can also be connected to external storage card, i.e., all these mobile devices can be expanded so that PDA and smart phones can not only support installation of software needed for learning, but also store massive learning materials for learners in learners. Then, these mobile devices can basically satisfy learners' normal learning.

Smooth access to the Internet. Both smart phones and PDA have its internal WAP browser and WWW browser, so learners can connect to the Internet through GPRS, Wi-Fi or CMCC-EDU, etc. to share, browse or upload information. [3]

Mobile devices have limited screen. Although until today, mobile devices' screens are mostly colorful with enlarging sizes, as mobile devices are portable, their screen size is still limited, which requires us to break up the entire learning resources into parts while reconstructing curriculum learning resources.

Good mobility is the biggest feature of all mobile devices. With such feature, scholars no longer have to worry out being unable to learn knowledge on the road. [4] Meanwhile, it allows learners receive information from everywhere at any time. Secondly, mobile devices are individualized. With the upcoming of diversified information, learning within the same class can no longer satisfy learners' learning demands, but mobile devices have provided individuals with different ways of learning at different purposes.

Mobile devices can provide contextualized learning so that learners are no long restricted to a small classroom, i.e., learners can apply their learned knowledge and skills into real situation at any time, and they can also communicate with experts, teachers and peers online.

Analysis of Learners. The ultimate goal of our study of mobile learning is to apply such convenient and efficient learning into our life and study, so we need to further analyze and study learners of such learning as how to efficiently and conveniently reflect such learning mode. And we also need to pay specific attention to learners in such construction because only learners can reflect our research value and the effect of our research in a certain field.

Research of Learners' Experience. All the experiment subjects received traditional education before contacting such new way of mobile learning, so we need to study learners' learning experience in traditional education and consider whether their experience can be useful in mobile learning, because learners are the final receivers of our results, so we need to construct mobile learning on their previous experience.

Study Learners' Self-Efficacy. We all know that it has been a short time since the development of mobile learning, which means for today's learners, they need to get out from the previous traditional teaching mode to face new mobile learning. This requires not only changes of learning ways, but also changes of thinking and their own. Therefore, we should consider whether students have get accustomed to passively accepting the classroom resources and whether they will take the initiative to learn the knowledge and finish homework timely without teachers' supervision, so we need to establish a feedback mechanism. [5] 
Analysis of Learners' Attitudes. As a new learning method, mobile learning develops in recent years. Learners have received many years of traditional education, and it still remains to be known what attitude they hold towards new learning method, i.e., we need learners' feedback of mobile terminal learning. Information disseminators adjust relevant strategies according to the feedback information.

Construction Principles of Mobile Curriculum Learning Resources. Construction of curriculum learning resources is not random, i.e., the construction should follow certain principle, such as:

Principle suitable for mobile learning. Compared with traditional learning, mobile learning happens in a relatively independent environment, and different learners have different ways of learning. Development of curriculum resources should be suitable so that learners can choose their own curriculum design according to features of their mobile device during mobile learning.

Principle of being scarce. It can be known from the above analysis of mobile device's features that mobile terminals have limited screen to display knowledge, and in mobile learning, learners can study at anytime and anywhere, i.e., learners learn during their spare time, so curriculum learning resources should be developed and constructed on the basis of being scarce so that mobile learning learners can master the knowledge within a short time, thus improving learning efficiency. [6]

Principle of being simple. Compared with traditional learning, another feature of mobile learning is that learners can study at any and anywhere, so that the study will not be interfered with by external environment. It is hard to complete the learning tasks with interferences, so classroom resources should be constructed to be simple. For example, preface of course design should be simple, picture allocation should be reasonable, text description should be concise, and key points and difficult points should be marked, etc.

Less input principle. Limited space of mobile device's screen decides that the quantity of information should be reduced during the construction of classroom learning resources.

\section{Curriculum Learning Resource Construction Model}

Role Assignment. Summarize the features of mobile terminal and mobile curriculum learning resources through the previous analysis, and then construction and planning of curriculum learning resources based on mobile terminal are carried out. First of all, roles should be studied: administrator, teachers and learners.

Administrator: There is an administrator in the construction of mobile curriculum learning resources, and the significance of this role is to manage teachers and students' personal information and publishing system notices as well as relevant information.

Teachers: In the construction of mobile curriculum learning, teachers' tasks mainly include constructing the curriculum, uploading learning contents and materials, solving students' questions, testing and evaluating students, giving students' feedback and communicating and discussing with students online.

Learner: The role learner plays an important role in the construction of mobile curriculum learning resources. The main task of learners is to browse relevant useful information on intelligent mobile phones or PDA, download their needed resources, and they can also learn and discuss online and finally form unified problems and give feedback to teachers. In the construction of mobile curriculum learning resources, these three roles are connected together through the network server so as to fulfill their respective tasks and purposes. [7] showing as Fig. 1. 


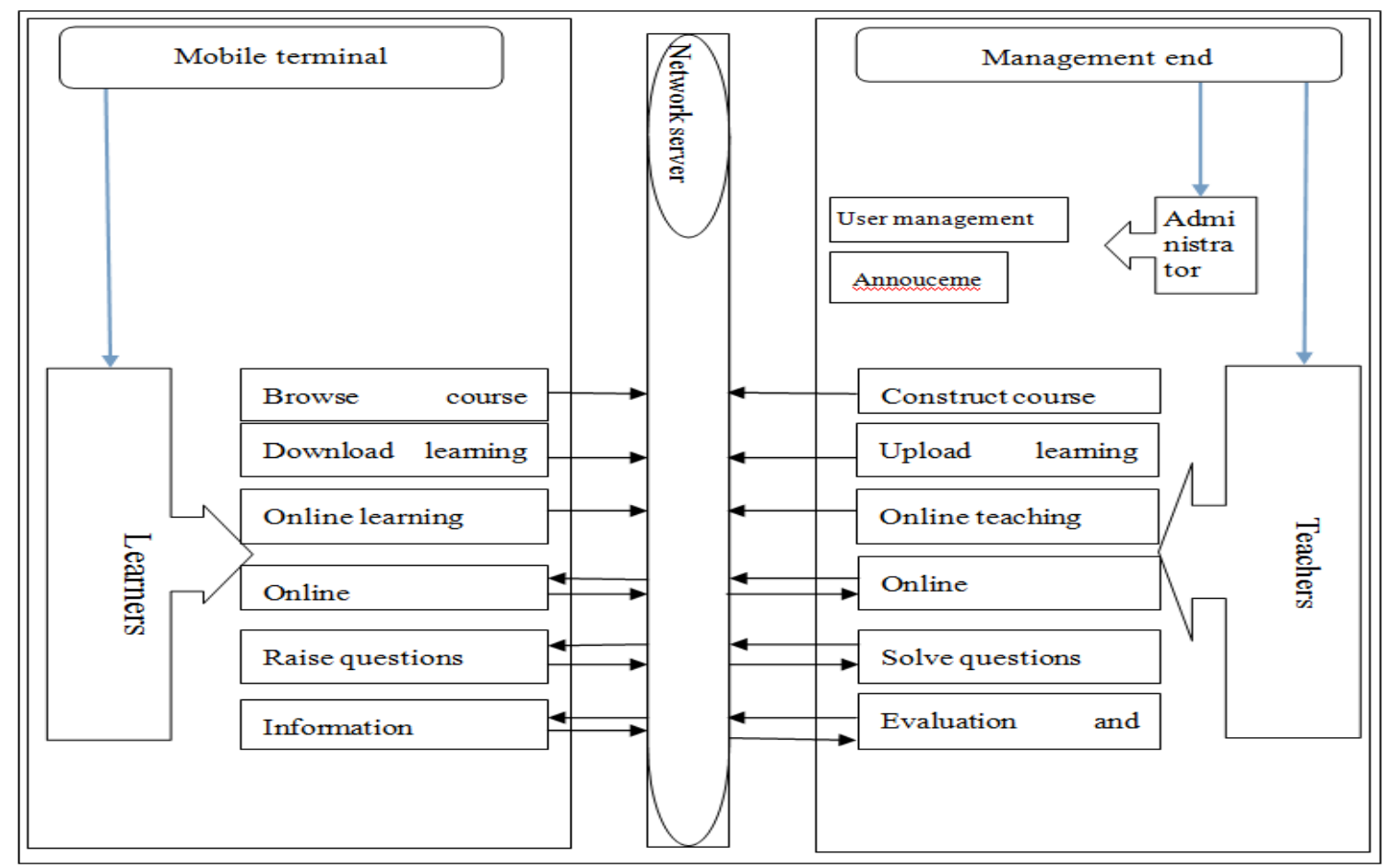

Figure 1. Diagram of Roles' Tasks

Create a Module. Construction of mobile curriculum learning resources mainly includes three modules: user registration and login, resource construction and navigation design [8], showing as Fig. 2.

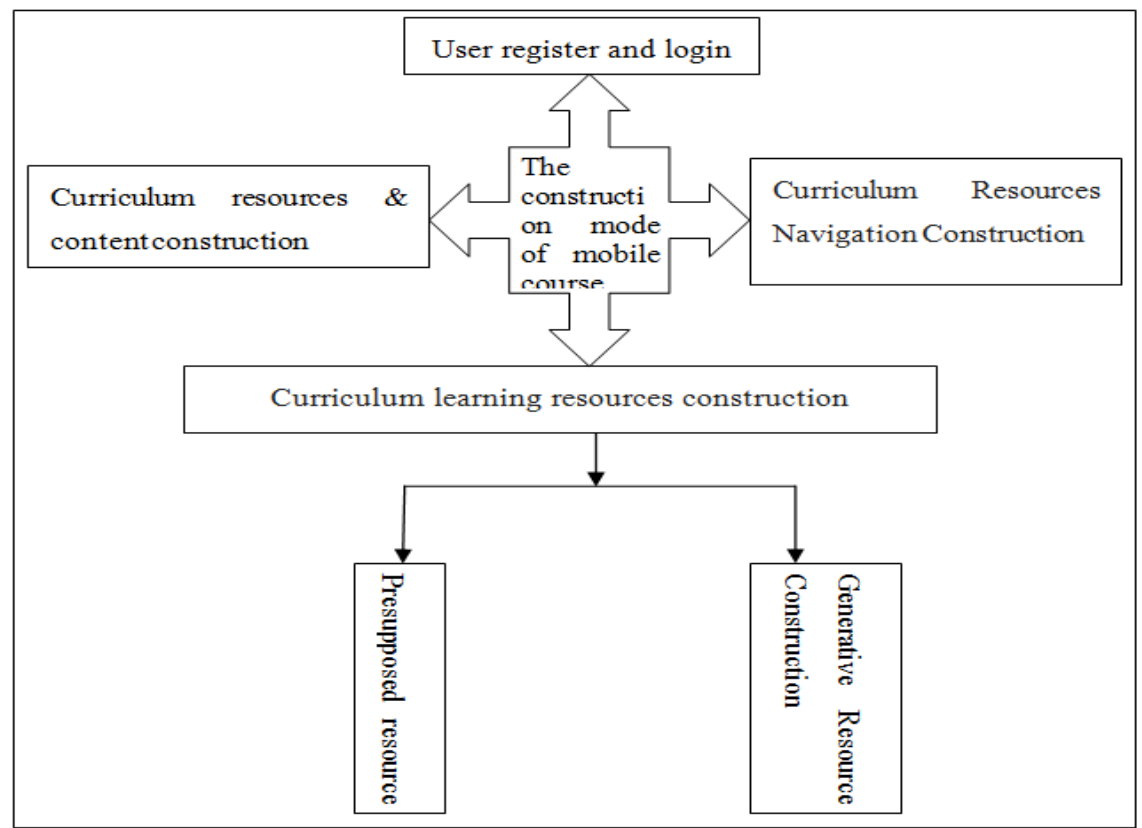

Figure 2. Construction Mode of Mobile Curriculum's Learning Resources

User Registration and Login Module: This module is designer to make teachers and learners login the mobile learning resource database through ID identification and then get corresponding rights.

Curriculum Resources Navigation Construction Module: The first page users enter after registration and login is a navigation page, which should be designed to be as simple as possible and easily to be seen so that learners can get into their desire page to learn within the shortest time. Navigation construction module is presented to users in the form of map [9].

Construction of Curriculum Resource Contents: Construction of the module of curriculum learning resource contents based on mobile terminal is mainly to simplify and integrate the contents 
of learning resources, mainly including the design of page color and how to highlight key points and difficulties. Content construction mainly includes online learning module, online communication module, discussion module and feedback and problem-solving module.

Construction of Curriculum Learning Resources: Learners who have logged in can browse and use the resource center module, which contains two kinds: preset resources and generative resources. Teachers need to use preset resources, which can also provide learners with generative resources. All these generative resources come from teachers' teaching courseware, teaching cases, teaching reflection and summary, etc., which can be used by learners after being uploaded by administrator and teachers. [10]

\section{Conclusions}

Mobile learning has become the focus of research in recent years because of its many advantages. It is the extension of learning pattern to integrate learning resources of curriculum with mobile devices. It also can improve people's learning consciousness to utilize their idle time, and to promote the efficiency of teaching and learning. In the process of mobile learning, learners can learn the content directly in real life. With the rapid development of technology and the improvement of mobile devices, the construction of learning resources based on mobile terminal will provide the necessary help for people's learning needs.

\section{Acknowledgement}

The study is funded by "Research on the Management Mode of Open Experimental Teaching Based on Projects" (No: 2014JG-2670030629).

\section{References}

[1] J.J. Xu, H. Zhang: On the Reform of Mobile Terminal Application Technology Curriculum Teaching [J]. Education reform, Vol.17 (2011) No.5, p44. (In Chinese).

[2] Y.M. Li: Analysis of the Current Status of Research into Mobile Learning in China from the Perspective of CNKI [J]. Journal of Shenyang Agricultural University (social science edition), Vol.17 (2013) No.5, p145. (In Chinese).

[3] M. Gao and J.J. Wu: H.J: Research and Design of Mobile Phone based M-Learning System [J]. Modern Education Technology, Vol.23 (2015) No.8, p122. (In Chinese).

[4] H.F. Ren and J. Zhao: Analysis of the Current Domestic and Foreign Research of Mobile Learning[J]. Adult Education, Vol.10(2013)No.1,p95. (In Chinese).

[5] X.Q. Wang: Research into Mobile Teaching System Design at Colleges and Universities (MS.D., Dalian Maritime University, China 2012),p421. (In Chinese).

[6] C.L. Feng: Research of Web-based College Mobile Learning Curriculum Design (MS.D., Harbin Normal University ,China 2012),p33351. (In Chinese).

[7] T.C. Feng: Research into Mobile Phone based Mobile Learning Support System(MS.D., East China Normal University, China 2015),p520. (In Chinese).

[8] J.Y. Ren: Research and Realization of Mobile Terminal Device Based Mobile Learning System (MS.D., Southwest Jiao tong University, China 2012),p226. (In Chinese).

[9] Z.Z. Wang: Research into Development of Experiment Learning Resources based on Mobile Terminal (MS.D., Jilin University, China 2014),p755. (In Chinese).

[10]L. Yang. Research into the Development and Application of Mobile Learning Resources based on Intelligent Learning End(MS.D., Hunan Normal University China 2014),p323. (In Chinese). 